\title{
Detection of Bone Fracture using Canny Edge Detection Techniques
}

\section{Rocky S Upadhyay ${ }^{1}$, Dr. Prakash Singh Tanwar ${ }^{2}$}

1Research Scholar, Computer Science and Engineering, Madhav University, Sirohi, Rajasthan, India 2Head, Department of CSE \& CSA, Madhav University, Sirohi, Rajasthan, India

\section{ABSTRACT}

The Image processing is most valuable aspect in medical services in now days. This technique is used in many other fields like bone fracture, cancer, detection nodules similarly many sun disciplines in medical division. The techniques of picture handling, for example, picture improvement, picture division and highlight extraction are utilized for crack recognition system. This paper utilizes Canny edge discovery strategy for segmentation. Canny strategy produces ideal data from the bone picture. The fundamental point of this exploration is to identify human lower leg bone crack from X-Ray pictures. The proposed framework has three stages, to be specific, preprocessing, division, and break identification. In highlight extraction step, this paper utilizes Hough change system for line identification in the picture. Highlight extraction is the primary errand of the framework. The outcomes from different investigations demonstrate that the proposed framework is extremely precise and proficient.

Keywords : Medical Image, Image processing, Canny Edge Detection

\section{INTRODUCTION}

Bone fracture is normal issue even in most created nations and the quantity of breaks is expanding quickly. Bone fracture can happen because of a straightforward mishap or various kinds of maladies. Thus, brisk, and exact finding can be pivotal to the accomplishment of any endorsed treatment. Contingent upon the human specialists alone for such a basic issue have cause grievous blunders. Thus, the possibility of programmed analysis system has consistently been an engaging one.[5] The principal objective of this paper is to distinguish the lower leg bone break from X-Ray pictures utilizing MATLAB software. The lower leg bone is the second biggest bone of the body. It is comprised of two bones, the tibia and fibula. The fibula bone is littler and slenderer than the tibia. In any case, the tibia break is most normally happening because of it conveys a huge bit of the body weight.[2] Among the four modalities (X-beam, CT, MRI, Ultrasound), X-beam determination is regularly utilized for bone fracture location because of their ease, fast and wide accessibility. In spite of the fact that CT and MRI pictures gives better quality pictures for body organs than X-beam pictures, the last are quicker less expensive, appreciate more extensive accessibility and are simpler to utilize couple of restrictions. In addition, the degree of nature of $\mathrm{X}$-beam pictures is sufficient with the end goal of bone fracture location. 


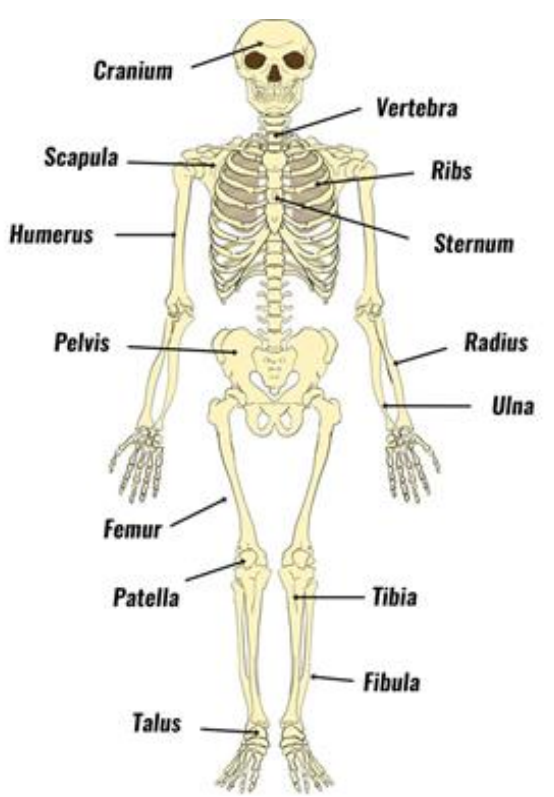

Fig. 1 Skeleton structure

\section{RELATED WORK}

S. K. Mahendran and S. Santhosh Baboo, et al. [3] displayed the Canny Edge Detection strategy to help radiologists in recognizing fractured bones from Xbeam pictures. They see that recreation result demonstrates that the framework should be enhanced its exhibition and lessen the reaction time. This work can be made end that the exhibition and precision of the discovery technique influenced by the nature of the picture. S. K. Mahendran and S. Santhosh Baboo, et al. [4] connected picture preparing systems to discover split in a bone. The creators think about the diverse edge locators and portray the points of interest and detriments of these identifiers. It is that the Canny technique produce similarly great edge with the smooth nonstop pixels and dainty edge. Sobel edge discovery technique can't create smooth and meager edge contrasted with Canny strategy. Be that as it may, same as different techniques, Sobel and Canny strategies additionally exceptionally touchy to the clamor pixels. At some point all the loud picture can't be sifted consummately. M. AL-AYYOUB and D. ALZGHOOL, et al. [6] break down a technique for processing neck-shaft plot for distinguishing femur fracture. This work is played out the extraction of femur form by utilizing a blend of calculations, in particular Canny edge identification and Hough change for recognizing noteworthy straight line and bend highlights, and dynamic shape mode with Gradient Vector Flow technique to snap on to the persistent femur shape dependent on the line and bend highlights distinguished. The creators portray that test outcomes demonstrate that the calculation effectively processed the neck shaft plots for $99.3 \%$ of the preparation and testing pictures.

\section{METHODOLOGY}

In this segment, the general framework configuration is depicted, picture pre-handling, picture division and fracture location. Fig. 2 demonstrates the stream chart of our created calculation. In the first place, client must information a picture to be prepared. The tried X-beam pictures were taken from nearby emergency clinic and Internet site.

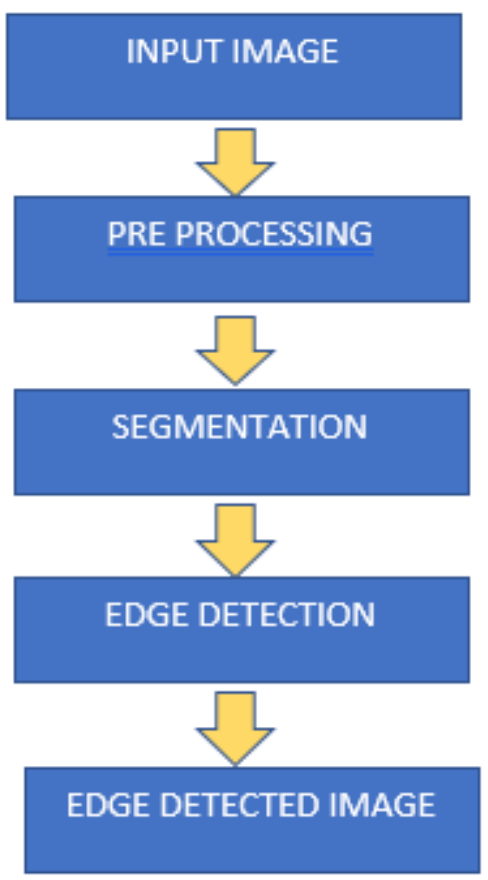

Fig. 2 System Flow 


\section{A. PREPROCESSING}

Pre-processing s used to apply some basic filters over an image. This image is allowed make upgrade into the quality. For edge detection, quality of image is most required. In this work basically the black and white and gray scale image. In this pro processing, gray scale image having the highest quality scale for getting better result in term of edge detection.

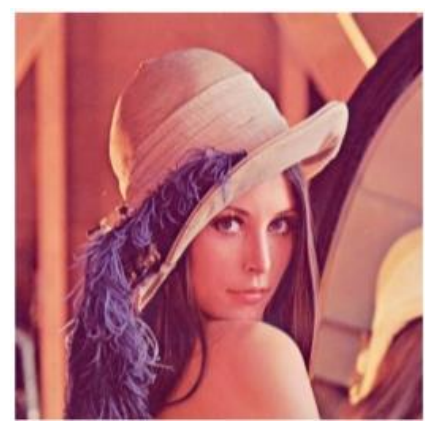

a) Original Image

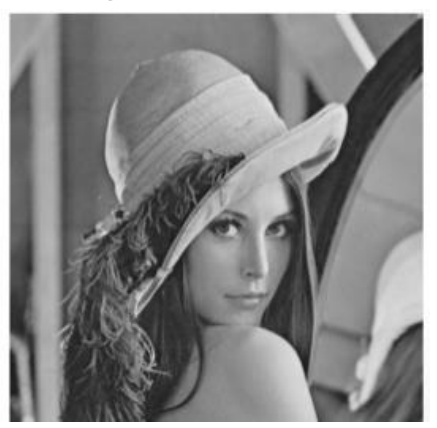

b) Gray Scale Image
Fig. 3 Result of Image Processing

Picture pre-handling is a phase in which the blunders of picture data which is recorded using the $\mathrm{x}$-beam sensors are controlled concerning brilliance esteems and geometry of the pixels. This stage is for diminishing commotion in pictures, highlighting the edges and to demonstrate pictures. Goals and difference improvement are fused into upgrade organize. Here, a $\mathrm{x}$-beam picture which is stacked into the system as info is changed over into a dark scale picture. The most broadly perceived commotion found in $\mathrm{x}$-beams is the Gaussian clamor which can be emptied by using the Gaussian channel. The edge and smoothness of the image are left undisturbed. Remembering the ultimate objective to get smoother and a wide Gaussian channel, a greater $\sigma$ is to be used. A standard picture with no clamor is the yield of this stage.

\begin{tabular}{|c|c|c|c|c|}
\hline $\begin{array}{c}\text { EDGE } \\
\text { DETECTION } \\
\text { TECHNIQUES }\end{array}$ & $\begin{array}{l}\text { LINGUISTIC } \\
\text { STRUCTURE }\end{array}$ & DEFINE & ADVANTAGE & DISADVANTAGE \\
\hline $\begin{array}{l}\text { Sobel Edge } \\
\text { Detector[15] }\end{array}$ & $\begin{array}{l}{[g, t]=\text { edge }(f,} \\
\text { "sobel", T, dir) }\end{array}$ & $\begin{array}{l}\text { The Sobel edge finder processes } \\
\text { the angle by utilizing the } \\
\text { accompanying discrete contrasts } \\
\text { among column and sections of a } \\
3 \times 3 \text { neighbourhood. }\end{array}$ & $\begin{array}{l}\text { Basic. Recognizes edges } \\
\text { and their introduction. }\end{array}$ & $\begin{array}{l}\text { Inaccurate and } \\
\text { sensitive to noise. }\end{array}$ \\
\hline $\begin{array}{l}\text { Roberts Edge } \\
\text { Detector[15] }\end{array}$ & $\begin{array}{l}{[\mathrm{g}, \mathrm{t}]=\text { edge (f, }} \\
\text { "roberts" T, } \\
\text { dir) }\end{array}$ & $\begin{array}{l}\text { The Roberts edge indicator } \\
\text { utilizes the imprints to rough } \\
\text { carefully the principal } \\
\text { subordinates as contrasts between } \\
\text { Neighbouring pixels. }\end{array}$ & Very quick to compute. & $\begin{array}{l}\text { It uses such a small } \\
\text { kernel, it is very } \\
\text { sensitive to noise. }\end{array}$ \\
\hline $\begin{array}{l}\text { Prewitt Edge } \\
\text { Detector[15] }\end{array}$ & $\begin{array}{l}{[\mathrm{g}, \mathrm{t}]=\text { edge }(\mathrm{f},} \\
\text { "prewitt", T, } \\
\text { dir) }\end{array}$ & $\begin{array}{l}\text { The Prewitt edge finder utilizes } \\
\text { the imprints to estimate carefully } \\
\text { the principal subsidiaries gx and } \\
\text { gy. }\end{array}$ & $\begin{array}{l}\text { Simple, detects Edge and } \\
\text { their orientation. }\end{array}$ & $\begin{array}{l}\text { Off base and } \\
\text { delicate to clamor. }\end{array}$ \\
\hline $\begin{array}{l}\text { Canny Edge } \\
\text { Detector[15] }\end{array}$ & $\begin{array}{l}{[\mathrm{g}, \mathrm{t}]=\text { edge }(\mathrm{f},} \\
\text { "canny", } \mathrm{T} \text {, } \\
\text { sigma) }\end{array}$ & $\begin{array}{l}\text { The count performs edge } \\
\text { interfacing by merging the slight } \\
\text { pixels that are 8-related with the } \\
\text { strong pixels. }\end{array}$ & $\begin{array}{l}\text { Smoothing impact to } \\
\text { evacuate clamor. Great } \\
\text { restriction and reaction. } \\
\text { Upgrades flag to clamor } \\
\text { proportion. Invulnerable to } \\
\text { boisterous condition. }\end{array}$ & $\begin{array}{l}\text { Hard to execute to } \\
\text { achieve continuous } \\
\text { reaction. Tedious. }\end{array}$ \\
\hline
\end{tabular}

Table 1 : Comparison of Edge Detection Techniques

\section{A. SEGMENTATION}
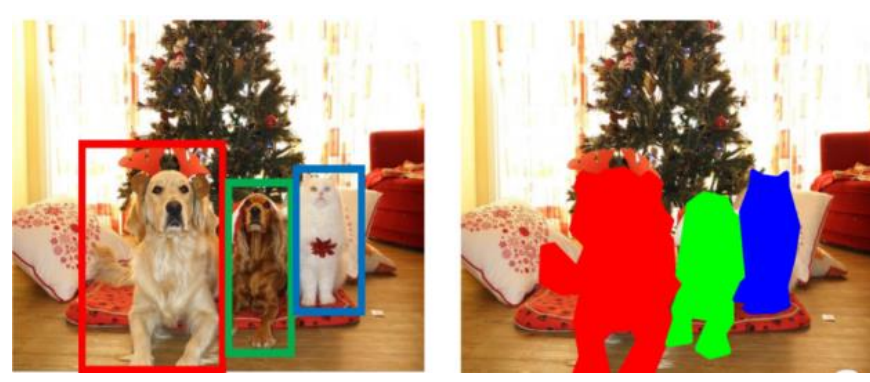

Fig. 4. Image Segmentation

Image segmentation process is useful in term of concentrating the main object rather than the whole picture that is visible. Segmentation process is most useful when you have to work with very intense with object. When you are going for use any edge detection technique than it will be very useful in term of accuracy. One important aspect is concern with this segmentation process that need the qualitive image for segmentation process that may be available using image pro-processing technique.

\section{B. FRACTURE DETECTION}

The last time of this system manages break affirmation. Till now the pictures are arranged and portioned so as to get fantastic pictures which have no clamor, enhanced and the edges been perceived. Directly, the straight lines in the picture are perceived since they are the most significant highlights in any picture. This element helps in 
describing the $\mathrm{x}$-beam as fractured or non-broke. [7]Hough change is used to perceive lines in pictures. It is used to extricate highlights like lines, shapes, and bends from the taken information picture which ought to be a paired picture. Here, $r=$ Perpendicular distance between the line in red and point of intersection of both the axes i.e. the origin

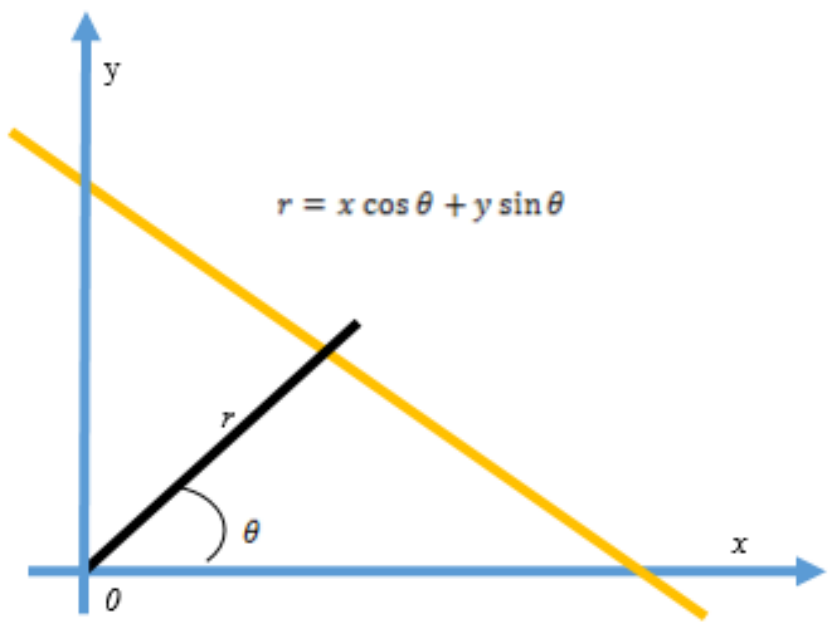

Fig. 5: Fracture Detection Equation

\section{CANNY EDGE DETECTION TECHNIQUE}

This edge discovery is made by Irwin Sobel and Gary Feldman and from now on is named after them. This Sobel administrator convolves two $3 \times 3$ divides with the basic picture to enlist the subordinate approximations. Out of them, one bit is used for logging the dimension changes and the other is used for logging vertical changes. Allow the basic picture to be characterized using An and after that Gx, Gy be two pictures which at the two centers contain the dimension and vertical auxiliary estimations autonomously.[9]

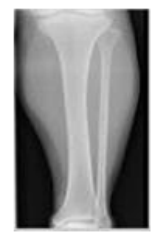

Original

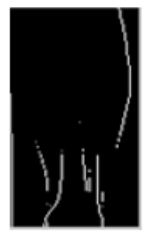

Sobel

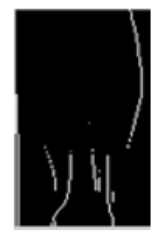

Prewitt

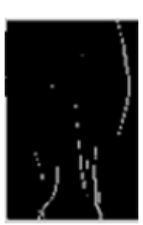

Robert

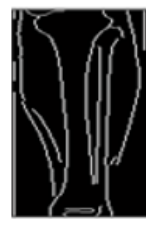

Canny
Fig. 6 Result Image of Diff. Edge Detectors
Picture division is the essential advance to examine picture and concentrate information from them. It is an activity of dividing a picture into a gathering of associated sets of pixels. The fundamental motivation behind division procedure is to get more data in the district of enthusiasm for a picture which aides in comment of the article scene. There are three principle methodologies of picture division which are area approach, limit approach and edge approach. In this work, edge based-based division is utilized which is increasingly reasonable for bone picture. Edge location is one of the most widely utilized tasks in applications that require determining objects' limits in a picture. It depends on examining the adjustments in the power in the picture. This paper portrays the correlation of the consequences of various edge indicators, for example, Sobel, prewitt, Robert and Canny finder. As per the trial results, Canny administrator is as opposed to other edge detectors. The edge limits of Sobel and prewitt edge indicators are not nonstop and don't demonstrate the significant imformation in light of the fact that the vast majority of them lost the significant structure. In Robert edge finder, the pixel of the picture is loud and the edges are not smooth and thin. In this paper, Canny technique is utilized to deliver great perspective on the bone structure.[7]

The Sobel edge discoverer forms the edge by using the going with discrete complexities among segment and areas of a $3 X 3$ neighbourhood where the centre pixel in each line and fragment is weighted by 2 to give smoothing. Limit edge just packages the primary assignments into one limit call and incorporates distinctive features, Recognition methods that are not implementable explicitly with imfilter.[4]

The Roberts edge pointer uses the engravings to unpleasant cautiously the chief subordinates as differences between Neighbouring pixels. Its general calling semantic structure is notice in examination 
table. The parameters of this limit are unclear to the Sobel parameters. The Roberts pointer is a standout amongst the most settled edge identifiers in modernized picture taking care of and it in like manner is the least troublesome.

The Roberts edge pointer uses the engravings to unpleasant cautiously the chief subordinates as differences between Neighbouring pixels. Its general calling semantic structure is notice in examination table. The parameters of this limit are unclear to the Sobel parameters. The Roberts pointer is a standout amongst the most settled edge identifiers in modernized picture taking care of and it in like manner is the least troublesome.

The semantic structure for the watchful edge pointer is notice in correlation table. Where $\mathrm{T}$ is a vector, $\mathrm{T}=$ [ T1, T2 ], containing as far as possible cleared up in stage 3 of the previous technique, in addition, sigma is the standard deviation of the smoothing channel.

\section{HOUGH TRANSFORMATION}

Importantly, this transformation is a linear type and mainly use for identifying the straight lines in any image. As mentioned in fig.7 it described ' $y=a x+b$ ' and also represented by graphic representation by using plotting points $(\mathrm{x}, \mathrm{y})$.

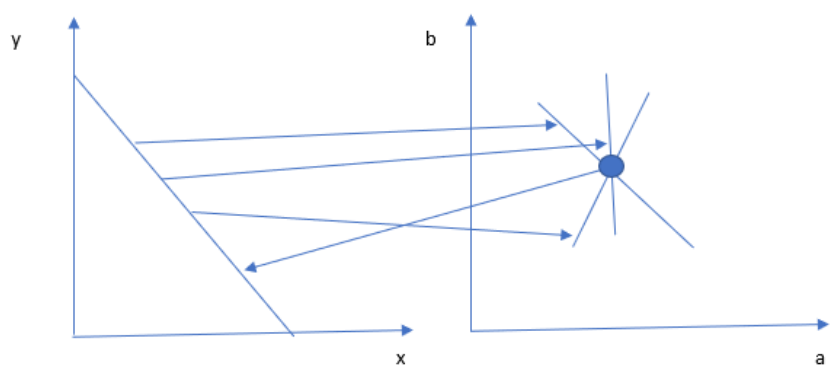

Fig.6 Image Space and Parameter Space
The main motive of this transformation to involve in the procedure is to make the identification of a straight lines rather than plotting points. But it works on basis of slot parameters and this require some interception parameter so for this require some plotting points for making such use of $(\mathrm{x}, \mathrm{y})$.

$$
\begin{gathered}
x \cos \theta+y \sin \theta=\rho \ldots \ldots \ldots \ldots \ldots \ldots \ldots \ldots(1) \\
\text { Here, } \quad \rho=\text { Distance (line and origin) } \\
\theta=\text { vector (origin to close point) }
\end{gathered}
$$

This approach is mainly used for to identifying the vertical lines only which its practically problems or limitation which can be noted. These problematic situations could be resolve by using below mentioned formula.

\section{EXPREMENTAL RESULT}

This experimental work is consisting with more than 100 images for proposed system trials and that is consist of various variety of human bones that shown in fig. 8(a-d). This process covers main demonstrate as per system work hand bones and wrist bones also considering. The experimentation has been finished utilizing 50 digital X-beam pictures of various bones. Subsequent to separating the straight lines, this framework is played out the break point identification. In this trial, the limit esteem 50 is utilized to discover the break point. This reference worth may should be changed if break is not in center of the bone. This framework utilizes $5^{\circ}$ weight worth or Hough pinnacle separation to discover vertical lines at which lines are situated. In the event that the weight esteem more than $5^{\circ}$, this line can't take as vertical straight line. This framework is relegated that the vertical straight line must have somewhere in the range of $80^{\circ}$ and $90^{\circ}$. On the off chance that there is more than one noteworthy point commitment there will be two pinnacles 
distinguished however just one pinnacle if there is just one noteworthy edge commitment.
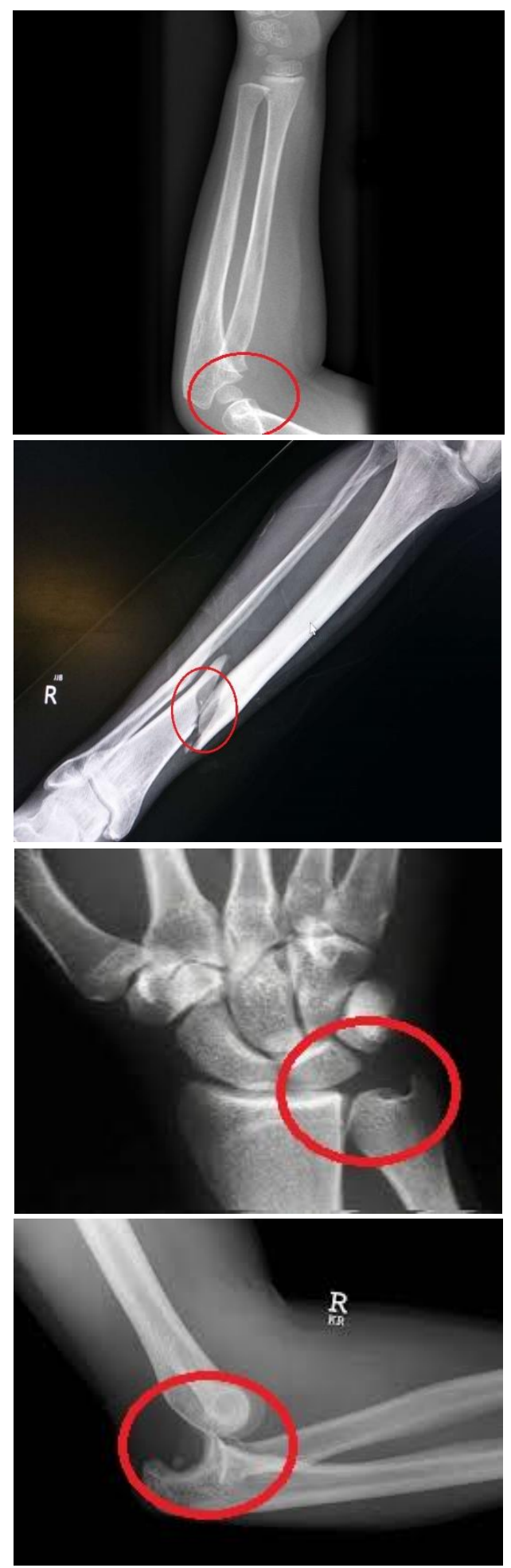

Fig. 8 Fracture Detection Results
Numerous X-beam pictures are gathered from neighborhood clinics and Internet sites. In this trial, 21X-beam pictures are tried. Among them, 50 pictures are fractures, and 10 pictures are typical Xbeam pictures. The calculation can't identify effectively in 6 break pictures. As indicated by the test outcomes, the performance of the identification strategy influence by the nature of the picture. This paper looks at the exhibitions of Canny edge locator in correlation with other edge finders, for example, Sobel, Prewitt, and Robert, which are connected to the X-beam pictures of lower leg bone. From the exploratory outcomes, it is seen that the Canny administrator gives better outcomes and creates great perspective on bone structure. After edge recognition, this framework talked about the exhibition of Hough change which is connected nervous picture to locate the straight line and edges at which bone pieces are found. The thought of Hough change is that each edge point in the edge guide is changed to every conceivable line. After that all, this framework decided if a fracture exists or not in the picture.

\section{CONCLUSION}

An automatic fracture detection and identification process is performed by the using canny edge detection techniques. This technique has allowed us to find the best output in term of edge detection. This technique is provided more accurate result in term of other comparative edge detection techniques. This proposed system is covering the portion of Hough transformation technique will help us in identifying the unshaped bones in various bone types. This system is used in all possible bone fracture detection. Before we had system that only usage in term of leg bones.

As referenced in the presentation, this paper considers the issue of distinguishing leg bone fracture. 


\section{REFERENCES}

[1]. "S. Myint, A. S. Khaing and H. M. Tun, "Detecting Leg Bone Fracture in X-ray Images", International Journal of Scientific \& Research, vol. 5, Jun. 2016, pp. 140-144".

[2]. "V. D. Vegi and S. L. Patibandla, S. SKavikondala and CMAK Z. Basha, "Computerized Fracture Detection System using xray Images", International Journal of Control Theory and Applications, vol. 9, Nov. 2016, pp. 615-621”.

[3]. "S. K. Mahendran and S. Santhosh Baboo, "An Enhanced Tibia Fracture Detection Tool Using Image Processing and Classification Fusion Techniques in X-Ray Images", Global Journal Of Computer Science and Technology, vol. 11, Aug. 2011, pp. 27-28".

[4]. "S. K. Mahendran and S. Santhosh Baboo, "Ensemble Systems for Automatic Fracture Detection", International Journal of Engineering and Technology (JACSIT), vol. 4, Feb. 2012, pp.7-10".

[5]. "M. AL-AYYOUB and D. AL-ZGHOOL, "Determining the Type of Long Bone Fracture in X-ray Images",WSEAS TRANSACATIONS on INFORMATION SCIENCE and APPLICATIONS, vol. 10, Aug. 2013, pp.261270".

[6]. “A. T. C, Mallikarjunaswamy M. S. and Rajesh Raman , "Detection of Bone Fracture using Image Processing Methods", International Journal of Computer Application, National Conference on Power \& Industrial Automation (NCPSIA, Aug. 2015, pp. 6-9".

[7]. "S Jayaraman, S Esakkirajan and T Veerakumar, Digital Image Processing, 2009, pp. 243-274".

[8]. "Chris Solomon, Toby Breckon, Fundamentals of Digital Image Processing,2011 pp. 90-108”.
[9]. "N. Umadevi, Dr. S. N. Geethalakshmi, "Multiple Classification System for Fracture Detection in Human Bone X-ray Images", in Proc. Third International Conference on Computing Communication \& Networking Technologies (ICCCNT), India , 2012, pp. 1-8”.

[10]. Rashmi, Mukesh Kumar, and Rohini Saxena, Algorithm And Technique On Various Edge Detection: A Survey, Department of Electronics and Communication Engineering, SHIATSAllahabad, UP.-India, Vol. 4, No. 3, June 2013.

[11]. Hao, S., Han, Y., Zhang, J., Ji, Z. (2013). Automatic isolation of carpal-bone in hand $\mathrm{x}^{-}$ ray medical image. In Informatics and Management Science I, p. 657-662. Springer.

[12]. Bielecki, A., Korkosz, M., Zielinski, B. Hand radiographs preprocessing, image representation in the finger regions and joint space width measurements for image interpretation. Pattern Recognition, 41(12) 3786-3798, 2008

[13]. R. Garnett , Timothy Huegerich and Charles Chui, 'A Universal Noise Removal Algorithm with an Impulse Detector' IEEE Trans. on Image Processing, Vol. 14, No.11, pp.17471754, 2005.

[14]. Gonzalez R.C., Woods R.E., Digital Image Processing, Addison Wesley, 2002.

\section{Cite this article as :}

Rocky S Upadhyay, Dr. Prakash Singh Tanwar, "Detection of Bone Fracture using Canny Edge Detection Techniques", International Journal of Scientific Research in Science and Technology (IJSRST), Online ISSN : 2395-602X, Print ISSN : 2395-6011, Volume 6 Issue 3, pp. 450-456, May-June 2019. Available at

doi : https://doi.org/10.32628/IJSRST2183132

Journal URL : https://ijsrst.com/IJSRST2183132 